\title{
Effect of bathing in a $0.1 \%$ aqueous solution of ethacridine lactate on selected physiological parameters of Cornu aspersum Müller edible snails
}

\author{
Jerzy Ziętek, Beata Dzięgiel, Alicja Wójcik ${ }^{\bowtie}$, Anna Wilczyńska, \\ Łukasz Adaszek, Stanisław Winiarczyk \\ Department of Epizootiology and Clinic of Infectious Diseases, \\ Faculty of Veterinary Medicine, University of Life Sciences in Lublin, 20-612 Lublin \\ Lis.Alicja@gmail.com
}

Received: September 19, 2019 Accepted: May 14, 2020

\begin{abstract}
Introduction: The prohibition of antibiotic use in edible snails obligates breeders to treat bacterial infections by different means, of which a common one is a bath in Gram-positive- and partially Gram-negative-bactericidal ethacridine lactate solution. The aim of the study was to determine the effect of bathing Cornu aspersum Müller snails in a $0.1 \%$ aqueous solution of ethacridine lactate on selected physiological parameters of haemolymph. Material and Methods: The study included 80 snails, divided into two equal groups (study and control). The study group was subjected to bathing in ethacridine lactate and the control group to bathing in tap water. Both groups were treated daily for seven days. The number of haemocytes in the haemolymph, the activity of alanine (ALT) and aspartate (AST) aminotransferases, and the concentration of urea were determined. Results: In the study group, after exposure to ethacridine lactate solution an increase in ALT activity, changes in the De Ritis ratio, an increase in the amount of haemocytes, and a decrease in body weight were found. No such changes were detected in the control group snails or in animals after the first bath. Conclusion: Multiple applications of a $0.1 \%$ ethacridine lactate bath may adversely affect Cornu aspersum Müller snails.
\end{abstract}

Keywords: Cornu aspersum Müller snails, heliciculture, ethacridine lactate, rivanol.

\section{Introduction}

Cornu aspersum Müller snails are an edible species, and for consumer safety reasons, no antibiotics can be used in the production cycle. In the case of bacterial infections in heliciculture operations, attempts are sometimes made to treat the snails by bathing them in a $0.1 \%$ ethacridine lactate solution.

According to some breeders, such a procedure has a positive impact on the health of the treated animals. Growers of edible snails recommend bathing in a $0.1 \%$ solution of ethacridine lactate in case of general weakness and increased mortality in the breeders of Cornu aspersum Müller and Cornu aspersum maximum. However, the benefit of this practice is not confirmed by scientific research.
Ethacridine lactate is an organic compound from the group of acridine dyes (13). It shows bactericidal activity against Gram-positive bacteria (streptococci) against many species of Gram-negative and pathogenic fungi (10). It is used in humans and veterinary medicine in the form of $0.1 \%$ aqueous solutions for topical use. Ethacridine lactate is applied in the treatment of purulent skin infections, infected mucous membranes and wounds, including wounds that are difficult to heal. The compound is also prescribed for genital inflammation, oral infections, skin abrasions, burns, and ulcers $(7,13)$. There are also literature reports on the use of acridine dyes in the treatment of diarrhoea and some parasitic (protozoan) diseases $(9,10,14)$. The mechanism of action of ethacridine lactate is based on the inhibition of microbial protein synthesis, whereby the compound 
binds to DNA of bacteria, inhibiting the ability to synthesise DNA and RNA in the cell. The structure of tricyclic ethacridine is interlocally incorporated between nucleotide base pairs in bacterial nucleic acid $(9,13,14)$. This changes the reading frame, causing incorrect transcription, further disturbances in protein synthesis, and the consequent death of the bacteria.

The aim of this study was to evaluate the effect of therapeutic baths in $0.1 \%$ ethacridine lactate solutions on selected physiological parameters of Cornu aspersum Müller snails.

\section{Material and Methods}

The study comprised 80 Cornu aspersum Müller snails at the age of nine months, with an average body weight of $9.8 \mathrm{~g}$, divided into two equal groups defined as $\mathrm{K}$ (the control group) and A (the study group). The animals were kept in plastic trays measuring $40 \times 30 \mathrm{~cm}$ and $25 \mathrm{~cm}$ high, covered with metal nets. The base was amoist coconut fibre substrate. The animals had constant access to fresh water placed in flat containers and were fed standard feed used at snail farms (composed of $30 \%$ calcium carbonate, $3 \%$ phosphorus carbonate, $18 \%$ protein, $40 \%$ starch, $3 \%$ fat, $4 \%$ fibre, and $1 \%$ vitamins and other minerals). Snails from group A were bathed in $0.1 \%$ ethacridine lactate water solutions for seven consecutive days, while those from group $\mathrm{K}$ had similar treatments using tap water.

The baths took place in plastic cuvettes with the dimensions $16 \times 12 \mathrm{~cm}$ and depth $10 \mathrm{~cm}$. They consisted in generous spraying of the snails in the containers and leaving them for $3 \mathrm{~min}$ in order to disperse the solution on their bodies.

On the first day of the experiment, 10 animals from each group were subjected to haemolymph extraction from the main vessel in the lung according to the procedure developed by the authors $(15,16)$, and then, the amount of haemocytes and the activity of aspartate (AST) and alanine (ALT) aminotransferases as well as the concentration of urea were determined. The haemocytes were counted in a Fuchs-Rosenthal chamber after the haemolymph was stained with an aqueous solution of crystal violet at a ratio of 10:1. The result obtained after dividing by 3 was given as the number of haemocytes in $1 \mu \mathrm{L}^{3}$. Biochemical parameters were determined with a BS-130 automatic chemistry analyser (Mindray Bio-Medical Electronics, Shenzhen, China), after the haemolymph had been centrifuged (1000 g, $3 \mathrm{~min}$ ). The studies were carried out on another batch of 10 snails from both groups on day 2 of the experiment, i.e. in animals that had been subjected to only one bath. The procedure was repeated on batches of 10 snails from both groups on day 7 (the end of the series of baths) and day 14 of the experiment (7 days after the end). Throughout the experiment, note was taken of the appetite and activity of the animals, and additionally, the snails were weighed on days 1,7 , and 14 of the experiment.
Due to the relatively small number of individuals used for the study, advanced statistical analysis of all results was not used. It was limited to determining the arithmetic mean and the standard deviation using the formula:

$$
\sigma=\sqrt{\frac{\left(x_{1}-\bar{X}\right)^{2}+\left(x_{2}-\bar{X}\right)^{2} \ldots\left(x_{n}-\bar{X}\right)^{2}}{n}}
$$

The results are presented in the form of line charts in which the units of mass were marked on the $\mathrm{X}$ axis and the selected variable on the $\mathrm{Y}$ axis.

\section{Results}

No deaths were observed in any of the groups of animals during the experiment. In group $\mathrm{A}$, snails increased in mobility, and more abundant mucus secretion was observed than in the control group. After day 5 of bathing in ethacridine lactate solution, a decrease in appetite was observed in group A, and this condition persisted until 5 days after the end of the bath series. On average, group A animals showed a 7\% decrease in body weight on day 14 of the experiment in relation to the measured values on day 1 . Weight fluctuations in the control group $(\mathrm{K})$ were less pronounced (on average up to $2 \%$ ) (Fig. 1). An analysis of haemocytes in the haemolymph showed a slight increase in the number in those bathed in $0.1 \%$ aqueous solutions of ethacridine lactate, but no differences in the number of haemocytes were observed in group $\mathrm{K}$ (Fig. 2). The urea concentration in the haemolymph did not show any significant changes in its value in any of the studied groups (Fig. 3). The biochemical study of haemolymph showed an increase in ALT activity in group A snails on days 7 and 14 of the experiment compared to the level on day 1 (Fig. 4). No significant changes were observed in the results of the biochemical test of haemolymph from the control group $\mathrm{K}$ (Figs 3 and 4). The results of aminotransferase activity were used to determine the De Ritis ratio, i.e. the AST to ALT ratio (Fig. 5).

\section{Discussion}

There are no guidelines for the treatment of bacterial infections in snails. In research on the methods of treatment of this type of infection, in addition to the evaluation of the effectiveness of the therapy, attention should be paid to the impact of the substance on the organism. Ethacridine lactate is active against bacteria, fungi, and protozoa, which can cause diseases in snails. It is often used by amateur growers for disinfecting and medicinal baths. The natural behaviour of snails causes them to come out of their shells and even lick the liquid from the ground and shell after a generous spray of water, so that the medicinal substance also comes into contact with parts of the body that are not covered by the shell. 


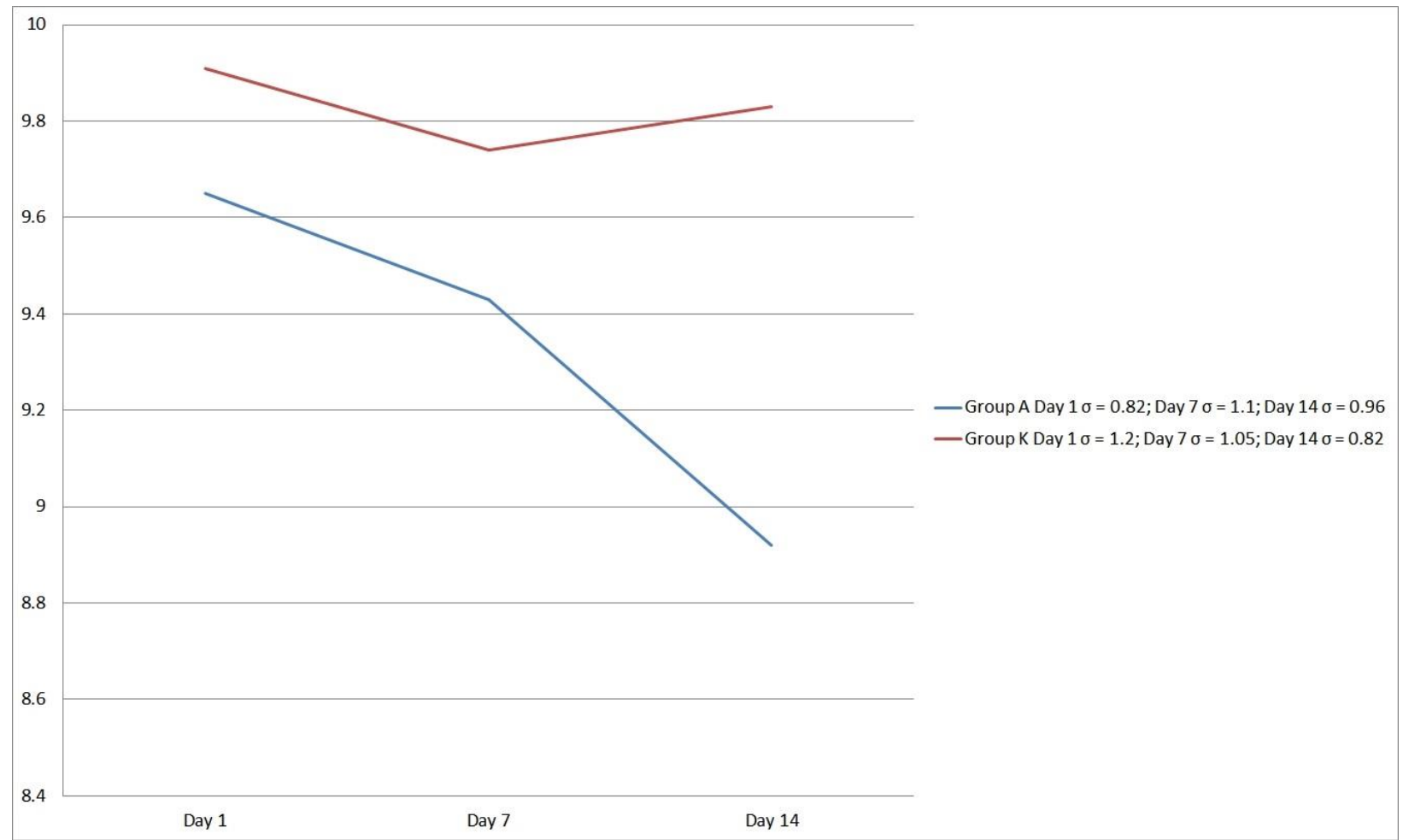

Fig. 1. Average body weight of Cornu aspersum Müller snails on days 1, 7, and 14 of the experiment. Group A series of seven baths $1 \times$ daily in $0.1 \%$ aqueous solution of ethacridine lactate; Group $\mathrm{K}$ series of seven baths $1 \times$ daily in clean tap water

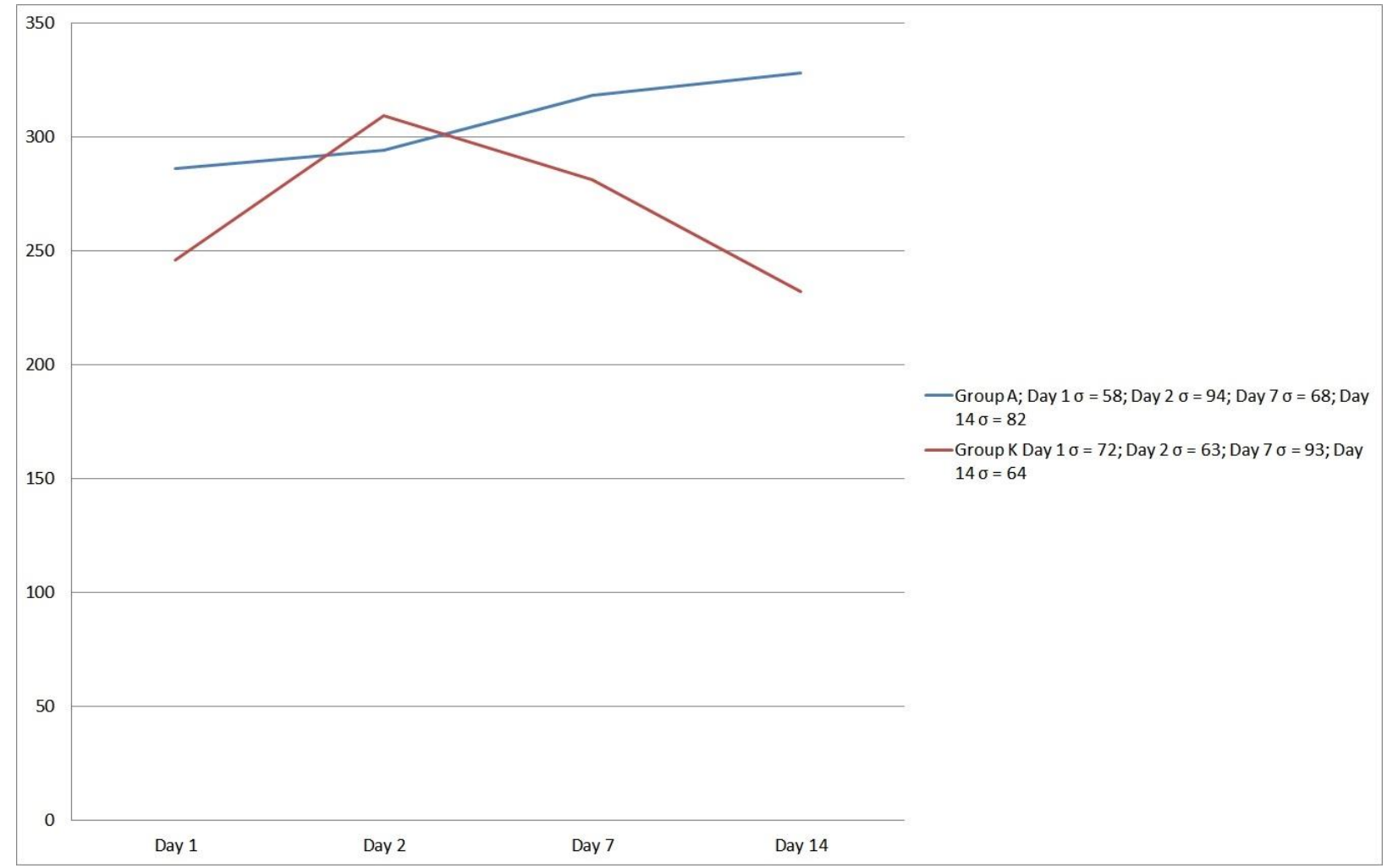

Fig. 2. Arithmetic mean of the obtained results of the haemocyte count in $\mu \mathrm{L}^{3}$ in haemolymph of Cornu aspersum Müller snails on days 1,7 , and 14 of the experiment. Group A - seven baths $1 \times$ daily in $0.1 \%$ aqueous solution of ethacridine lactate; Group $\mathrm{K}-$ series of seven baths $1 \times$ daily in clean tap water 


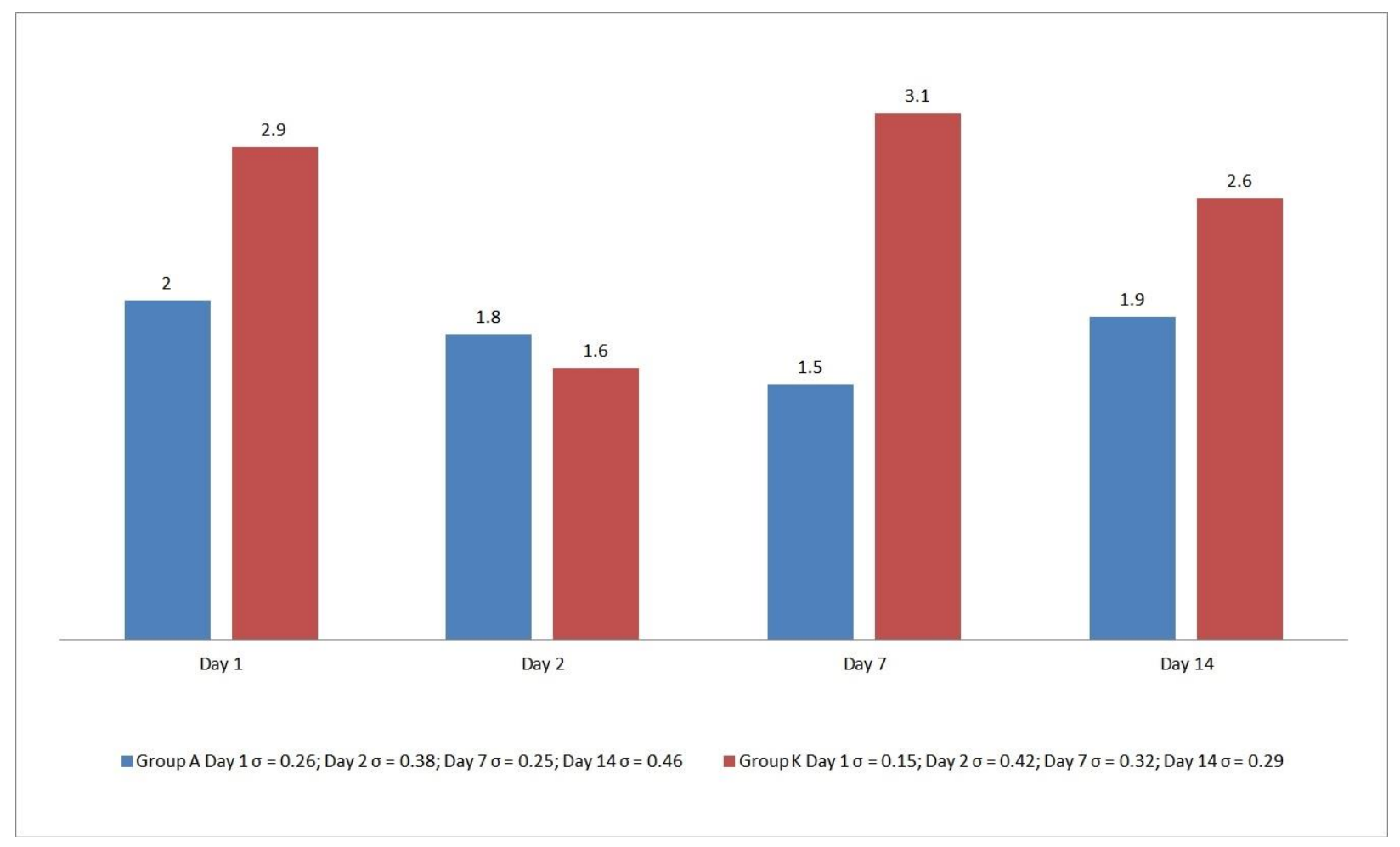

Fig. 3. Arithmetic mean of the obtained results of the urea $(\mathrm{mg} / \mathrm{dL})$ in the haemolymph of Cornu aspersum Müller snails on days 1,7 , and 14 of the experiment. Group A - seven baths $1 \times$ daily in $0.1 \%$ aqueous solution of ethacridine lactate; Group K series of seven baths $1 \times$ daily in clean tap water

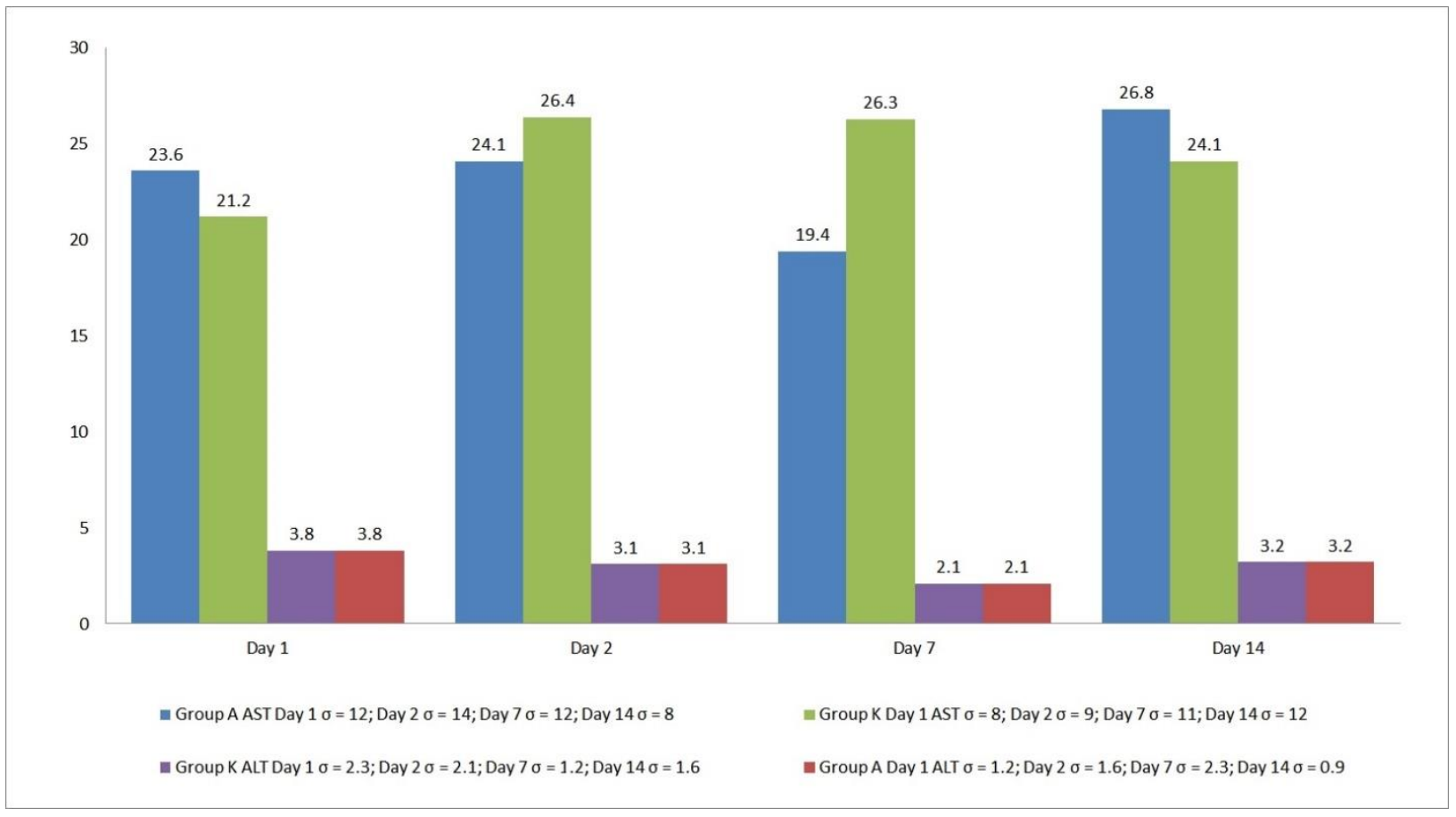

Fig. 4. Arithmetic mean of the obtained results of the ALT and AST activity (U/L) in the haemolymph of Cornu aspersum Müller snails on days 1,7 , and 14 of the experiment. Group A seven baths $1 \times$ daily in $0.1 \%$ aqueous solution of ethacridine lactate; Group $\mathrm{K}$ series of seven baths $1 \times$ daily in clean tap water 


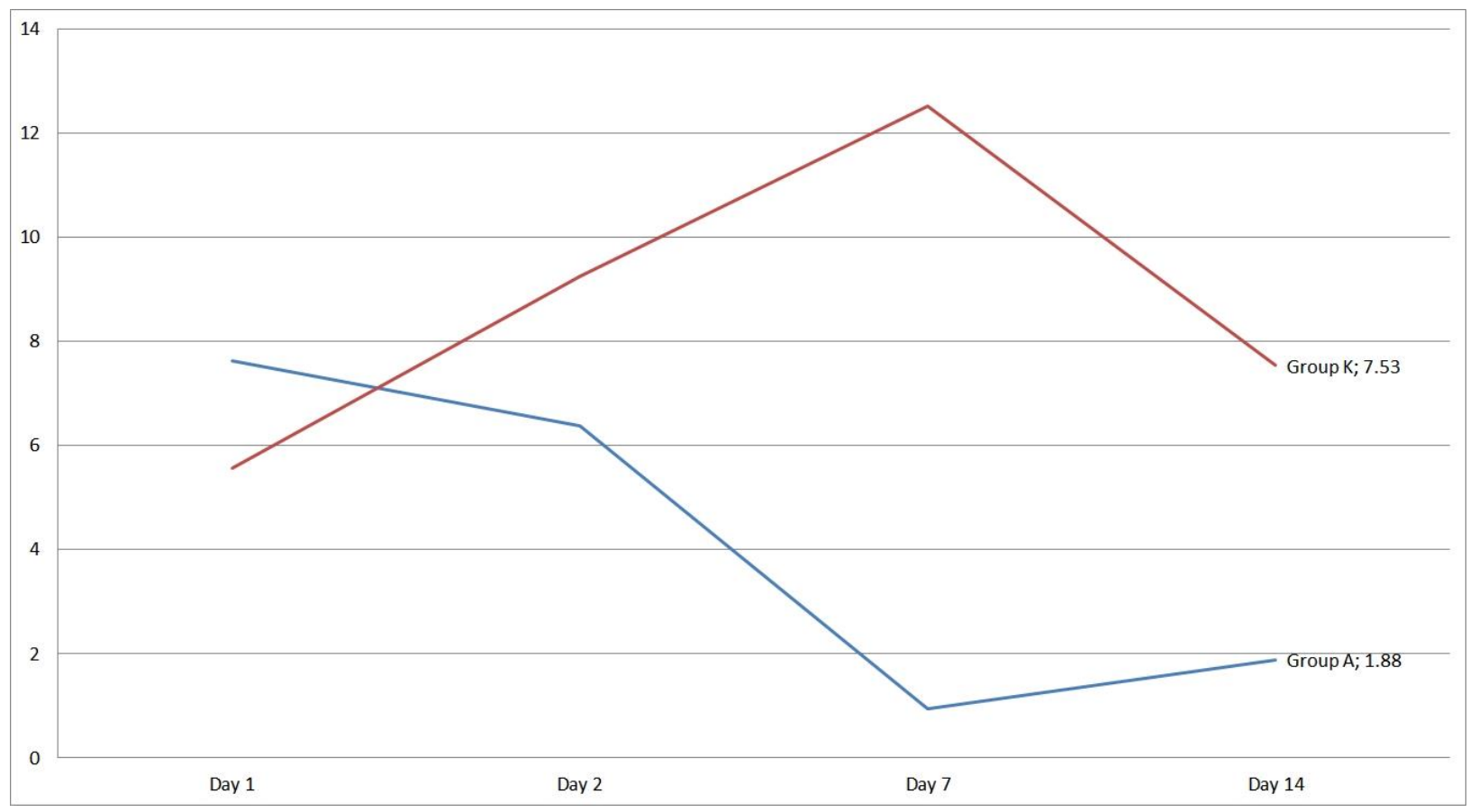

Fig. 5. De Ritis ratio values in the studied groups of animals (arithmetic mean of individual results)

The epithelial layer covering the snail body is relatively thin (5) compared to that of mammals, so it cannot be excluded that ethacridine lactate may penetrate into the body of the snail, which may increase its action.

The choice of haemolymph parameters to analyse in our studies was dictated by the need to determine the widest possible influence of ethacridine lactate on the snail organism. Haemocytes are immune cells capable of phagocytosis, and an increase or decrease in their number affects the ability of the animal to fight infection (1). The Fuchs-Rosenthal chamber haemocytes test is relatively simple to perform, and the large cell counting fields are well suited to the assessment of fluids that do not contain too many morphotic elements. In our research, we have shown an increase in their number when exposed to irritants. The number of haemocytes in the haemolymph continued to increase in each successive measurement in group A snails, and finally, on day 14 of the experiment, the number of haemocytes was $14 \%$ higher than before the start of the baths in the ethacridine lactate solution.

The activity of aminotransferases is a reflection of the function of the hepatopancreas and also illustrates in some way the metabolic rate. According to our research (15) and the observations of other authors $(3,8)$, low AST and ALT levels are characteristic of snails that show poor appetite, while an increase in the aforementioned parameters may indicate intoxication. Alanine aminotransferase (ALT) and aspartate aminotransferase (AST) are (organically) non-specific enzymes involved in protein metabolism. The measurement of their activity is used in mammals for the diagnosis of liver, heart, and skeletal muscle diseases (4). In the case of poisoning with liver damage, their activity increases. Comparing AST to ALT, we can determine the De Ritis ratio used in the diagnosis of liver damage. Normally, it should be more than 1, while a value below 0.9 may indicate intoxication (6).

Our previous results (15) indicate that the activity of aminotransferases increases in the snail haemolymph when hepatotoxic substances are administered. In the present study, the increase in ALT activity in the haemolymph of the snails treated with ethacridine lactate and differences in De Ritis ratio between the $\mathrm{K}$ group and the A group (below 1 in the third and below 2 in the fourth measurement for the A group compared to above 12 and above 7 for the $\mathrm{K}$ group at the same measurement times) may have resulted from the toxic effect of the substance in question, which may have entered the snail body during bathing per os and through the epithelial layer, causing damage to the digestive gland. It is worth noting that changes in ALT activity and De Ritis ratio values were observed after the series of seven baths, while a single bath in $0.1 \%$ ethacridine lactate solution did not cause visible changes in the biochemical picture of the haemolymph.

Urea concentration may increase with tissue degradation, which is characteristic of cachexia $(11,12$, 16). In this study, no significant changes in the value of this parameter were observed in any group of animals. In group $A$, the appetite decreased after five days of bathing. The loss of appetite and weight may have been caused by the irritating effect of ethacridine lactate on the subjects. The irritant effect was also manifested in increased animal mobility and mucus secretion $(2,5)$. 
In conclusion, it should be stated that a series of seven baths in a $0.1 \%$ aqueous solution of ethacridine lactate over a seven day period adversely affected the tested animals, while a single application of this type of bath seems to have no effect on health. The information obtained from growers indicates that the one to three treatments they use most often, probably do not cause adverse changes in the snails, and therefore, they recommend this type of treatment for parasitic infections and bacterial diseases. The results of the presented studies do not confirm the therapeutic effect of such procedures. It should be remembered that baths could be irritating to snails, their repetition for several days could result in a decrease in appetite, and an increase in ALT activity in the haemolymph may indicate that ethacridine lactate enters the bodies of the treated animals causing damage to the digestive gland. Therefore, care should be taken when using the preparation in the form of therapeutic baths for snails. If further attempts are made to use ethacridine lactate as a non-antibiotic chemotherapeutic agent for snails, studies on the distribution, metabolism, and route of administration of the substance should be continued.

Conflict of Interests Statement: The authors declare that there is no conflict of interests regarding the publication of this article.

Financial Disclosure Statement: The present study was self-funded.

Animal Rights Statement: None required.

\section{References}

1. Adamowicz A., Bolaczek M.: Blood cells morphology of the snail Helix aspersa maxima (Helicidae). Zoologia Poloniae 2003, 48, 93-101.

2. Birati A., Conazzi M., Gioria M.: An ultrastructural study of connective tissue in mollusc integument: II Gastropoda. Tissue and Cell 2001, 33, 426-438.
3. Bislimi K.R., Bojniku H., Gashi A., Grapici L., Halili J., Mazreku I., Halili F.: Seasonal changes in the hemolymph biochemistry of snail Helix aspersa. FASEB J 2012, 26,735.

4. Johnson D.E.: Special considerations in interpreting liver function tests. Am Farm Physician 1999, 59, 2223-2230.

5. Luthel D.L., Martins A.W., Degrup-Olsen I., Boer H.H.: Gastropoda: Integument and Shell. In: Microscopic Anatomy of Invertebrates, edited by F.W. Harrison, A.J. Kohn, J. Wiley-Liss, New York 1997, pp. 461-495.

6. Nyblom H., Bjornsson E., Siren M., Aldenbory F., Almer S., Olsson R: The AST/ALT ratio as an indicator of cirrhosis in patients with PBC. Liver Int 2006, 26, 840-845.

7. Petrikate V., Trasevicius E., Paulonis A.: New ethacridine derivatives as potential antifungal and antibacterial preparations. Medicina (Kaunas) 2007, 43, 657-663.

8. Pinheiro J., Gomes E.M., Chagas G.M.: Aminotransferases activity in the hemolymph of Bradybaena similaris (Gastropoda, Xanthonychidae) under starvation. Mem Inst Osvaldo Cruz 2001, 96, 1161-1164.

9. Plein K., Burhand G., Holtz J.: Treatment of chronic diarrhea in Crohn disease. A pilot study of the clinical effect of tannin albuminate and ethacridine lactate. Fortschr Med 1993, 111, 114-118.

10. Rising T.J., Fromscon J.M., Johnson P.: Further absorption studies with anti-diarrhoeal agent ethacridine lactate in the dog. Arzneimittelforschung 1978, 28, 631-635.

11. Tunholi V.M., Lustrino D., Tunholi-Alves V.M., Mello-Silvia C.C., Maldonado A. Jr, Pinheiro J., Rodrigues M.: Biochemical profile of Biomphalaria glabrata (Mollusca: Gastropoda) after infection by Echinostoma paraensei (Trematoda: Echinostomatidae). Parasitol Res 2011, 109, 885-891.

12. Tunholi-Alves V.M., Tunholi V.M., Arural L.S., Mota E.M., Maldonado A. Jr, Pinheiro J., Garcia J.: Biochemical profile of Achatina fulica (Mollusca: Gastropoda) after infection by different parasitic loads of Angiostrongylus cantonensis (Nematoda: Metastrongylidae). J Invertebr Pathol 2010, 124, 1-5.

13. Wainwright M.: Acridine - a neglected antibacterial chromophore J Antimicrob Chemiother 2001, 74, 1-13.

14. Ziegenhagen D.J., Raedsch R., Kruis W.: Traveler's diarrhea in Turkey. Prospective randomized therapeutic comparison of charcoal versus tannin albuminate/ethacridine lactate. Med Klin (Munich) 1992, 87, 637-639.

15. Ziętek J., Guz L., Winiarczyk S., Szkucik K., Ziomek M., Wysokowski M., Madany J., Adaszek Ł.: Study on establishing normal ranges of chosen biochemical parameters of hemolymph of Cornu aspersum maxima and Cepaea nemopralis gastropods. Pol J Vet Sci 2018, 21, 445-449.

16. Ziętek J., Guz L., Wójcik A., Winiarczyk S., Adaszek Ł.: The concentration of urea in hemolymph as a marker of health in Lissachatina fulica and Cornu aspersum edible snails - a preliminary study. Pol J Vet Sci 2019, 22, 259-262. 